the femur. You would not think of applying this principle of opposing muscular action to any other part of the body as here. We seem to forget that some of the muscles pull inward, while others pull directly upward; so it is absolutely necessary that we apply two forces, and that we overcome the muscular action so that the resultant of the two applied forces shall be in the direction of the neck of the femur and give the result of one acting in the long axis of the body, and the other in an outward direction.

\section{HERPES ZOSTER OPHTHALMICUS WITH BRIEF REPORT OF FIVE CASES.*}

\section{WM. C. BANE, M.D.}

Clinical I'rofessor of Ophthalmology and Otology, Denver College of Medicine; Ophthalmologist and Otologist to St. Joseph's Ilospital; House of the Good Shepherd; National Jewish Hospital for Consumptives; C., R. I. \& I'. Ry.; Consultant for Diseases of the Nose and Throat to the State Home for Dependent Children. DENVER, COLO.

Iferpes zoster ophthalmicus has been well known for the past third of a century. It is an acute inflammatory affection appearing in the course of the first and second branches of the fifth nerve, and is almost invariably unilateral. It occurs in elevated groups of firm oval or circular vesicles, on an edematous base, s.t the terminal points of the nerve filaments. The groups of vesicles do not all appear at once and their area is limited to the median line, and to filaments of the branches involved in the inflammation.

Herpes zoster ophthalmicus is a neuritis in which the ganglion of Gasser is involved, as has been proven by De Wecker. Chareot and others have demonstrated that in herpes zoster the ganglion of the posterior roo of the spinal nerve is inflamed.

The discase is characterized by severe pain, which u.ralally precedes the eruption by a period varying from hours to several days. The pain is generally sharp and shooting, and interferes with sleep and labor, but sometimes the pain is dull and causes less disturbance.

In the ophthalmic type, the first branch is the one mos frequently involved, which includes the upper lin, forehend as far as the scalp, and also the nose. The second branch includes the lower lid, superior maxillary region, upper lip, and over the malar bone.

When the nasal branches are involved, the cornea is very likely to suffer, though exceptions to this rule have beteri observed.

The error of diagnosing herpes zoster ophthalmicus as facial erysipelas has frequently been made. Some of the typical features of the two diseases are as follows: HERPES ZOSTER OPHTHALMICUS. ACUTE FACIAL ERYSIPELAS.

1. It develops as a bright I. It develops as a purplishred inflammation limited to red inflammation that spreads one side of the face, and ap- over all parts, without regard pears in clusters of firm vesi- to the median line; the vesicles on an edematous base, cles, when they appear, are in that does not spread when large blebs.

once developed.

2. The eruption is preceded for hours or days by severe neuralgic pains, and as a rule no fever or rigors mark the disease.

3. The inflammation being of a neuroulc origin, it is lim. ited to tissues where the nerve filaments terminate.

2 . It is ushered in by a chill, and marked elevation of temperature, also a burning sensation in the inflamed tissues. A dull headache may be present.

3. The inflammation being due to infection by the streptococcus erysipelatis, spreads through the lymph channels. and when deep invades the lymphatic glands.

* Read at the Fifty-second Annual Meeting of the American Medical Association, in the Section on Ophthalmology, and approved for publication by the Executive Committee of the Section
Drs. J. A. I.ppincott, Casey A. Wood and H. V. Wurdemann.
4. The inflamed points are exceedingly painful to the touch.

כ. Groups of punched-out scars are invariably left in the wake of the vesicles and remain through life.

The following cases of herpes zoster ophthalmicus have come under my observation:

Case 1.-On Jan. 8, 1891, I saw Mrs. H. C. K., in consultation with Dr. C. Jane Vincent of Alleghany City. Some seventeen days previous to my visit, the patient had developed herpes zoster ophthalmicus of the left frontal and temporal regions. The patient had suffered severe pain in the head and the left eye. The vision was reduced to counting fingers at two feet. She had considerable congestion of the eyeball, and a small central uicer of the cornea. The iris was free and responded to light and accommodation. One week after my first visit the ocular congestion had subsided, the corneal ulcer had healed and vision so improved that she could see the features of a face a few feet from the eye. No record was made of any vesicles on the nose.

CASE 2.--Rev. J. S. T. M., aged 65, consulted me May 5, 1891. He stated that one month previously his left eye had been injured by a bit of steel. His family physician removed the foreign body three days after the accident. He then developed what was diagnosed facial erysipelas, the disease being confined to the left side of the forehead and nose with involvement of the left eyc. He gave a history of having had three corneal ulcers and iritis of the left eye. Upon examination I found a moderately congested eyeball and a slight opacity of the cornea marking the location of the ulcers. There were also several pigment deposits on the anterior capsule of the lens, marking the points where the iris had been adherent. On the forehead, the supraorbital ridge and the nose were the scars where vesicles had existed. Vision of the right eye was $6 / 12$, and that of the left eye 6/18. The patient remained under my care for about a month, during which time his vision improved and the congestion of the eyeball in great part disappeared.

CASE 3.-In February, 1896, I was called by Dr. J. W. Higgins to see Mrs. J.W. P. The patient was a delicate woman of 56 years of age. She was suffering with intense neuralgic pains in the left side of the head and face. Her face presented the typical appearance of an aggravated form of herpes zoster ophthalmicus, involving the first and second branches of the trigeminus. The area involved was of a bright-red color with large groups of vesicles on the forehead, nose and cheek. The left eye was moderately congested and painful, but no involvement of the cornea existed. The nearalgic pains were excruciating. Two weeks after $I$ saw the patient she became insane and was taken to an asylum, where she remained for four years, finally dying without regaining her mental balance. Upon inquiry of her husband I learned that she had manifested some evidence of mental disturbance for a month previous to the revelopment of the herpes zoster.

CASE 4.-E. A. P., aged 36, a nurse, was referred to me Nov. 30, 1899, by Dr. H. T. Pershing, on account of having some irritation of the left eye. Patient came to Colorado eight weeks previously, owing to some pulmonary disease. Two weeks after reaching Denver he was taken with chills, having three or four daily for a week, with a temperature of 100 to 104 . On Oct. 24, 
1899 , the left side of his face became of a bright-red color and somewhat swollen. The inflammation extended from the scalp down the median line, including the left half of the upper lip and aeross the cheek and temple. Patient applied to a hospital and was refused admittance, on the ground that his facial disease was believed to be contagious, but was referred to another hospital where he was admitted as a case of facial erysipelas and there he remained four weeks. Three days after, the face became inflamed, clusters of clear firm vesicles formed on the inflamed area, those on the lefl side of the nose being as large as the little-finger nail. Crusts appeared later and those on his nose became quite dark in color and the patient states that the crusts were removed about the ninth day after the vesicles appeared, leaving painful ulcers. For the next twenty-four hours he experienced an intense itching and burning sensation over the affected area, and the following day a new crop

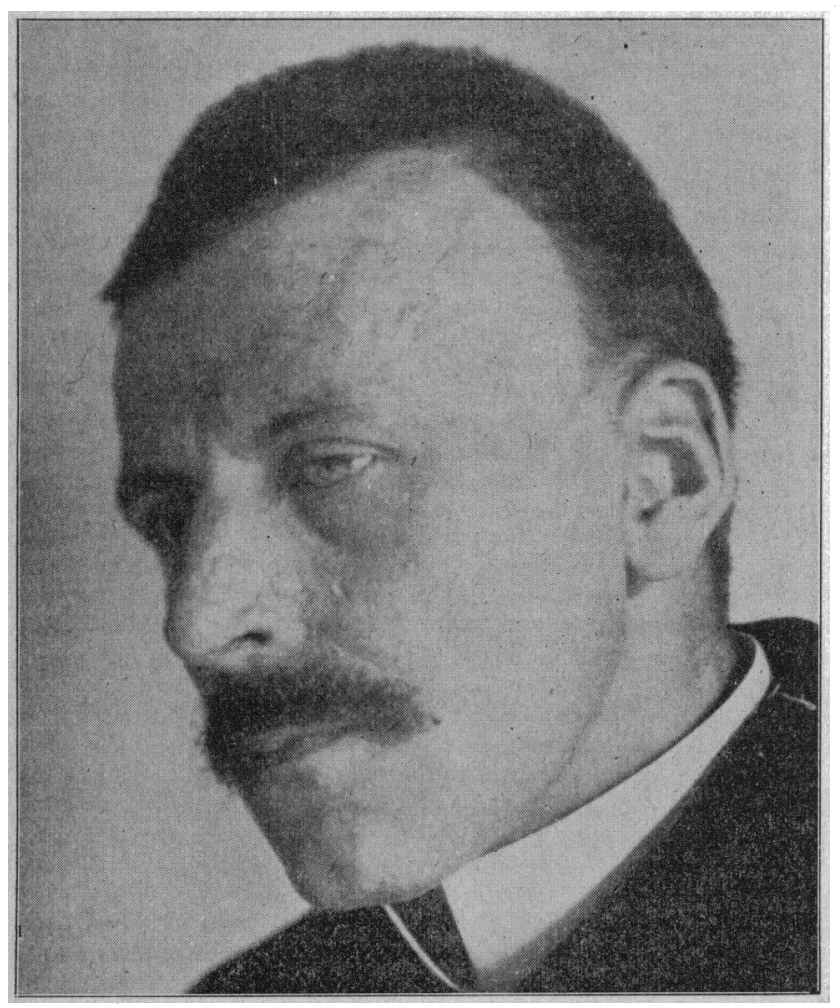

Herpes zoster ophthalmicus.

of vesicles appeared and the left eye became very painful, the lids swollen, and of a purplish hue. Some twelve hours later most of the swelling subsided and the color changed to a bright red. The eye remained painful and he was unable to bear the light. Upon examination (five weeks after the first appearance of the disease) vision of the right eye $6 / 6$, left eye $6 / 30$. Marked photophobia existed in the left eye. The lids were somewhat swollen, of a reddish hue and tender to the touch. Partial anesthesia of the upper lid existed. Conjunctiva was slightly congested, the cornea clear and partially anesthetic. Pupil was moderately dilated from atropin. There was hyperemia of the retina, otherwise no fundus changes perceptible. The left side of the nose showed loss of tissue and considerable cicatricial contraction, not unlike the appearance left $b y$ smallpox or a burn. In the scalp near the forehead on the line of the parting of the hair was a cluster of depressions marking the seat of a group of ulcers. The depressions on the temple were not very plainly outlined.
One clean-cut depression existed on the cheek about an inch to the left of the lower half of the nose. The skin of the left temple was anesthetic on a line with the brow, and partial anesthesia existed over the rest of the temple and forehead to the median line and back into the scalp.

Some error of refraction was manifest in left eye, the correction of which brought the vision up to $6 / 12$. Patient remained under my care for several weeks, during which time the neuralgic pains diminished, the photophobia became less and a slight improvement in the anesthetic areas occurred.

Case 5.-Miss A., aged 22, came under my notice in November, 1900, through the courtesy of Dr. J. M. Blaine, under whose care the patient was at that time. She was passing through a moderate attack of herpes zoster ophthalmicus of the left side of her face, involving the first two branches of the fifth nerve. Three group of vesicles were present, one on the forehead, one on the temple and one on the lower eyelid. The eye was free from irritation. The patient had a great deal of neuralgic pain for several days previous to the developing of the eruption. After the disease had been properly diagnosed and the patient was improving she met auther physician who told her she had facial erysipelas.

Remarks:-The first case was typical in its course and sequelæ. The disease was correctly diagnosed and the indications met by the attending physician. The second case, an intelligent gentleman, had been under the care of an eye surgeon of repute, and yet the disease had been diagnosed facial erysipelas. The sequelæ were typical of herpes zoster ophthalmicus, in the scars on the face and maculæ of the cornea, the latter being with the rule, that is, when the nasal branches are implicated. The third case presented an interesting feature in that the patient manifested some mental disturbance a month previous to the development of the herpes, and two weeks afterwards became so unbalanced mentally as to require close confinement, in which she was kept until she died. However, I am led to believe that the herpes zoster was merely a coincident in the mental disease and not a part of the central nervous affection. The fourch case, a nurse, spent a month in a hospital under the care of a very successful practitioner, and yet the true nature of the disease was overlooked. The affection was an exception to the rule, in that the cornea escaped ulceration, while the inflammation of the nose was very severe, bordering onto the gangrenous type. The fifth case had a moderate attack, neither the nose or the eyeball being involved.

Two of the five cases were males. Four were leftsided. Three of the five were diagnosed cases of facial erysipelas. Two had corneal ulcers. Two had severe nasal involvement without implication of the cornea.

The Medical Balloon-Ascents.-Four balloons were placed at the disposal of certain physicians of Paris who wished to study the effect of high altitudes on the blood, etc., free from the fatigue of mountain climbing. Drs. Tissot, Hallion, Raymond, Jolly and Henri were among those who made the ascent. The tests were made on large dogs or on the physicians themselves. The results harmonized in ever case and showed a marked and rapid increase in the number of red corpuscles in the blood when an altitude of about 9000 feet was reached, but this increase disappeared during the descent. Dr. Gaule had previously reported similar tests on himself, his wife and chil. dren, with the same result, the temporary augmentation of the red corpuscles at the high altitudes. The physicians communicated their experiences to the Society of Biology. 